\title{
Parathyroid carcinoma in multiple endocrine neoplasia type 1. Case report and review of the literature
}

\author{
Carlos del Pozo ${ }^{1}$, Luis García-Pascual' ${ }^{1}$, Montserrat Balsells ${ }^{1}$, \\ María-José Barahona', Enrique Veloso², Clarisa González ${ }^{3}$, Jordi Anglada-Barceló ${ }^{1}$ \\ ${ }^{1}$ Service of Endocrinology, ${ }^{2}$ Service of Surgery, ${ }^{3}$ Deparment of Pathology, Hospital Universitari Mútua de Terrassa, \\ Terrassa, Barcelona, Spain
}

\begin{abstract}
Parathyroid carcinoma is an infrequent cause of primary hyperparathyroidism. Although hyperparathyroidism in multiple endocrine neoplasia 1 (MEN1) syndrome is the most common manifestation, parathyroid carcinoma is rare. We report a male patient who was diagnosed at 44 years of age with parathyroid carcinoma in the context of MEN1 syndrome coincident with a malignant gastrinoma and non-functioning adrenal adenomas. A genetic analysis revealed the mutation W183C in exon 3 of the MEN1 gene. The diagnosis of carcinoma was made after parathyroid surgery; there had been no clinical suspicion prior to surgery, as the patient had presented only moderate hypercalcemia. Our review of the few published cases of parathyroid carcinoma in MEN1 syndrome reported in the literature indicates that MEN1 gene mutations do not confer a greater risk for parathyroid carcinoma and do not appear to differ from sporadic parathyroid carcinoma.
\end{abstract}

Key words: Hypercalcemia, Multiple endocrine neoplasia type 1 (MEN 1), Parathyroid carcinoma, Parathyroid surgery, Primary hyperparathyroidism

\section{INTRODUCTION}

Multiple endocrine neoplasia 1 (MEN1) is an inherited disorder with dominant transmission that is due to mutations in the gene that encoding for the protein menin, which acts as a tumor suppressor. ${ }^{1}$ The clinical expression of MEN1 is variable and is

\section{Address for correspondence:}

Carlos del Pozo, Service of Endocrinology, Hospital Universitari Mútua de Terrassa, Plaza Dr. Robert 5, 08221 Terrassa, Barcelona, Spain, Tel.: +347365050, Fax: +347365059, E-mail: 11774cpp@comb.cat

Received 21-11-10, Revised 19-01-11, Accepted 10-02-11 characterized by the concurrent appearance of adenomas of the parathyroid glands, neuroendocrineenteropancreatic tumors, and pituitary adenomas, as well as other types of less frequent tumors, such as adrenal cortical tumors, carcinoid tumors, lipomas, etc. The diagnosis of this syndrome is made when two of the three principal tumor types are present.

Primary hyperparathyroidism (HPT) in MEN1 syndrome is the most common manifestation presenting in over $90 \%$ of patients between the ages of 40 and $50 .{ }^{2}$ In contrast to what occurs in the sporadic HPT, in which a single parathyroid adenoma is present, in 
MEN1 more than one parathyroid gland is affected, which implies a more complex treatment and a higher probability of recurrence.

The appearance of a parathyroid carcinoma in MEN1 is very rare with few references in the literature.

We present a patient with MEN1 with a parathyroid carcinoma associated with a gastrinoma and non-functional adrenal adenomas.

\section{CASE REPORT}

We report a 50-year-old male patient, with a history of allergy to iodine contrasts, one episode of renal colic from renal lithiasis, traumatic fracture of the sternum, pneumonia with pleural parapneumonic effusion, obesity (current body mass index of $36.6 \mathrm{Kg} /$ $\mathrm{m}^{2}$ ), and a smoker until 2004.

In 2003, he was examined after presenting digestive symptomatology of two years' duration consisting of abdominal pain and diarrhea. Abdominal computed tomography (CT) and magnetic resonance imaging (MRI) detected three solid nodular lesions in the pancreas of between 13 and $19 \mathrm{~mm}$ in size with a homogenous contrast uptake. Two of these were located in the head of the pancreas and the other at the union of the pancreatic body and tail. Furthermore, the patient also had hepatic steatosis and two adrenal nodules, one in each gland, which were hypodense and $15 \mathrm{~mm}$ in size without accompanying hormonal hypersecretion.

A blood gastrin level of $135 \mathrm{ng} / \mathrm{L}$ (reference range $<100$ ) was registered. Secretin stimulation test showed a basal gastrin level of $134 \mathrm{ng} / \mathrm{L}$ with a peak value of $420 \mathrm{ng} / \mathrm{L}$ at $10 \mathrm{~min}$.

In June 2004, he underwent a procedure consisting of puncture of the largest tumor located in the pancreatic body through intraoperative ultrasound. The cytology disclosed malignant cells of neuroendocrine origin. With the diagnosis of multicentric gastrinoma a total duodenopancreatectomy together with a splenectomy and colecistectomy was carried out. Macroscopic inspection of the pancreatectomy specimen revealed a total of 7 tumors, the size of which ranged from 5 to $29 \mathrm{~mm}$. A histological study definitively confirmed the diagnosis of a malignant multifocal neuroendocrine tumor with positive immunoreactivity for synaptophysin and chromogranin, and metastasis in 3 of the 9 peripancreatic ganglia but without evidence of metastasis in 10 mesenteric ganglia.

The patient was referred to us because of diabetes mellitus secondary to pancreatectomy and treatment was initiated with multiple doses of insulin.

In July 2004, at 44 years of age, he was diagnosed with primary HPT based on the detection of hypercalcemia, an intact parathyroid hormone (PTH) level of $204 \mathrm{ng} / \mathrm{L}$ (reference range 7-53), and a urine calcium excretion of $13.4 \mathrm{mmol} / 24 \mathrm{~h}$. During the two-year follow-up period, the serum calcium concentration oscillated between 2.9 and $3.1 \mathrm{mmol} / \mathrm{L}$ (reference range 2.3-2.7). Upon review of his clinical history, it was disclosed that in 1998 elevated serum calcium had been detected on two occasions (2.8 and 2.9 $\mathrm{mmol} / \mathrm{L}$, respectively).

A cervical ultrasound revealed 4 thyroid nodules (between 5 and $16 \mathrm{~mm}$ ) and below the right thyroid lobe a hypoechoic mass measuring 11x6x6 mm which appeared to correspond to the parathyroid.

A scintigraphic study with technetium Tc 99 mlabeled methoxyisobutyl isonitrile (TcMIBI) showed an uptake compatible with an adenoma of the right inferior parathyroid gland.

A bone densitometry showed osteoporosis ( $\mathrm{T}$ score: -3.44 in the lumbar spine, -2.69 in the femoral neck).

On suspicion of MEN1, a genetic study was carried out and the mutation $\mathrm{W} 183 \mathrm{C}$ in exon 3 of the MEN1 gene was detected. This mutation was later detected in one of his two children, a daughter, who at that time was 10 years old. The patient is an only child and his parents, who had died, had no known antecedents suggestive of any illness associated with MEN1.

In the context of MEN1, a study of the pituitary hormones was carried out but no abnormality was found. A pituitary MRI was also performed in which a pseudonodular image of $5 \mathrm{~mm}$ was seen in the sequences with contrast that was not conclusive for microadenoma. 
In October 2006, the patient underwent parathyroid surgery. During the procedure, a hardened right inferior parathyroid gland was observed which had an appearance suggesting malignancy. The surgeon removed the parathyroid gland along with surrounding fatty tissue, the right thyroid lobe, as well as a hyperplasic right superior parathyroid and a lower left parathyroid of normal appearance. The pathology study revealed a right inferior parathyroid of 17 $\mathrm{mm}$ maximum diameter that histologically showed dense solid areas consisting of oncocytic cells without atypical cytology or mitotic figures, alternating with zones of trabecular growth pattern intermixed with desmoplastic stroma and fibromixoid zones, focal necrosis, and atypical cytology (Figure 1). The tumor activity had infiltrated the capsule and the peripheral fibroadipose tissue (Figure 2), as well as focally the thyroid gland. No vascular or perineural infiltration was observed. Based on these findings a diagnosis of parathyroid carcinoma was made. In the hemithyroidectomy specimen, nodular hyperplasia with regenerative changes and hyperplasia of $\mathrm{C}$ cells were observed. Neoplasic infiltration was not observed in five ganglia isolated in the pathological specimen

After the surgery the patient experienced subclinical hypothyroidism, for which he has been on substitution treatment with thyroxin $50 \mathrm{mcg} / \mathrm{day}$. Calcium and PTH levels normalized and have remained so up to the present.

It should be mentioned that in the first gastrin determination carried out after the pancreatic surgery, the gastrin values were slightly elevated $[123 \mathrm{pg} / \mathrm{ml}$ (N 13-115)]. However, all of the later determinations were normal (between 78-96 pg/ml).

In addition, in the TC abdominal studies done since the pancreatic surgery there has been no evidence of the presence of hepatic metastasis or changes in the size of the adrenal nodules.

The patient is currently asymptomatic and leading a normal and active life while undergoing treatment with insulin, thyroxin, lansoprazol, and pancreatic enzymes.

\section{DISCUSSION}

Parathyroid carcinoma is a rare affliction and

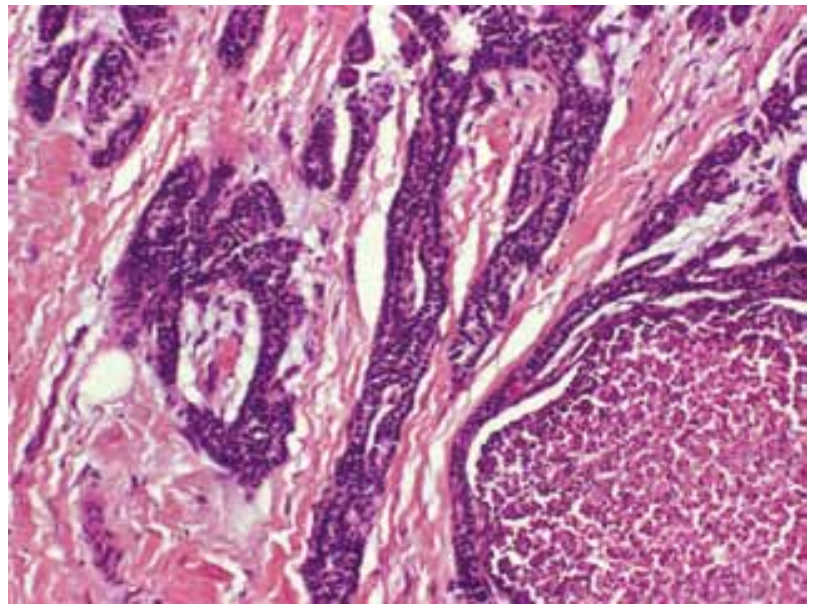

Figure 1. Light microphotograph of parathyroid carcinoma showing trabecular pattern with areas of necrosis. (Hematoxylin-eosin stain; original magnification $\mathrm{x} 40$ ).

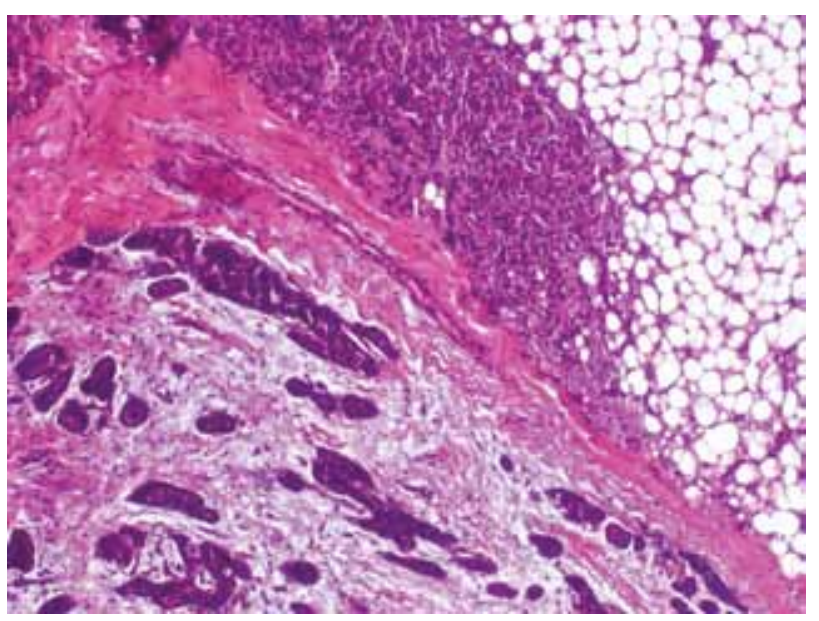

Figure 2. Light microphotograph of parathyroid carcinoma showing areas of trabecular pattern with desmoplastic reaction and invasion of the capsule and of the peripheral fibroadipose tissue. (Hematoxylin-eosin stain; original magnification x 40).

represents $0.5-5 \%$ of all cases of primary HPT. ${ }^{3,4}$ The difference in prevalence between series is due, in part, to the diagnostic criteria considered, especially from the histopathologic point of view.

There is no currently available method to definitively differentiate between difficult cases of parathyroid adenomas and carcinomas. Therefore, the definitive diagnosis continues to be based on the invasion of adjacent structures and/or the existence of metastasis, although the latter frequently does not occur until several years after the first surgery. 5,6 
Immunostaining techniques may provide additional information, but again this is not definitive..$^{7-9}$

Some factors appear to contribute to the occurrence of parathyroid carcinoma, such as cervical radiotherapy, hyperplasia or adenomas of the parathyroid glands, and HPT secondary to chronic renal insufficiency. ${ }^{10}$

Parathyroid carcinoma may occur in certain genetic syndromes. Thus, in hyperparathyroidism-jaw tumor (HPT-JT), in which isolated HPT is associated with ossifying fibromas of the jaw, the incidence of parathyroid carcinoma is high (up to $15 \%$ ). ${ }^{10,11}$ HPT-JT is an autosomal dominantly inherited disorder caused by mutation of the gene HRPT2 that encodes for parafibromin. Mutations of this gene can also frequently be found in sporadic parathyroid carcinoma. In fact, one study detected the presence of these mutations in 15 out of 20 patients with parathyroid carcinoma and no family history of the disease. ${ }^{12}$

Another study analyzed tissue from 28 sporadic parathyroid carcinoma cases. Somatic MEN1 mutations were found in 3 of $23(13 \%)$ and HRPT2 mutations in 4 of $27(15 \%)$. These results suggest that not only HRPT 2 mutations but also MEN1 mutations may play a role in sporadic parathyroid cancer formation. ${ }^{13}$

Genetic alterations have not been identified in the majority of cases of familial isolated HPT syndrome. ${ }^{14}$ In some cases, however, mutations of the MEN1 or of the HRPT2 gene have been identified and in these cases parathyroid carcinoma has been detected..$^{11,15}$

In contrast to germline mutations of the HRPT2 gene that appear to predispose to parathyroid carcinoma, the contribution of germline MEN1 mutations to the development of parathyroid carcinomas is almost negligible. In the bibliographic search only five cases of parathyroid carcinoma in MEN1 were found (Table 1). ${ }^{16-19}$ In two of these cases, included in the same publication, ${ }^{16}$ no mutation of the MEN1 gene was detected, leading the authors to suggest that this could indicate the presence of one or more novel occult mutations with a more aggressive phenotype. Nevertheless, in other cases which were similar to those described in this report, mutations of the MEN1 gene were detected (Table 1).

With respect to clinical evaluation, there are some aspects suggestive of parathyroid carcinoma, such as the presence of severe hypercalcemia $(>3.6 \mathrm{mmol} / \mathrm{L})$ accompanied by related symptomology such as weakness, weight loss, anorexia, nausea, vomiting, polyuria, and polydipsia. Generally, malignancy is related to markedly elevated levels of PTH (between 3 and 10 times normal values). In other cases it is the presence of a palpable cervical mass in the context of HPT that

Table 1. Literature data of parathyroid carcinoma in patients with MEN1

\begin{tabular}{|c|c|c|c|c|c|}
\hline $\begin{array}{l}\text { Authors } \\
\text { (Reference) }\end{array}$ & $\begin{array}{c}\text { Age } \\
(\text { years })\end{array}$ & Gender & $\begin{array}{c}\text { Mutation } \\
\text { MEN1 GENE }\end{array}$ & Associated tumors & $\begin{array}{c}\text { Clinical presentation } \\
\text { of HPT }\end{array}$ \\
\hline Agha et al, 2007 (16) & 69 & $\mathrm{~F}$ & Not identified & $\begin{array}{c}\text { Macroprolactinoma } \\
\text { Non-functioning pancreatic tumor }\end{array}$ & $\begin{array}{l}\text { Severe symptomatic } \\
\text { hypercalcemia }\end{array}$ \\
\hline Agha et al, 2007 (16) & 32 & M & Not identified & Gastrinoma & $\begin{array}{l}\text { Severe symptomatic } \\
\text { hypercalcemia }\end{array}$ \\
\hline Shih et al, 2009 (17) & 53 & $\mathrm{~F}$ & $\begin{array}{l}\text { c. } 1406-13 \\
\text { up } 8\end{array}$ & $\begin{array}{l}\text { Non-functioning pituitary adenoma } \\
\text { Gastrinoma }\end{array}$ & $\begin{array}{l}\text { Severe symptomatic } \\
\text { hypercalcemia }\end{array}$ \\
\hline Sato et al, 2000 (18) & 51 & $\mathrm{~F}$ & $\begin{array}{l}842 \text { delC } \\
\text { exon } 4\end{array}$ & None* & Moderate hypercalcemia \\
\hline Dionisi et al, 2002 (19) & 35 & M & Not specified & Gastrinoma & $\begin{array}{l}\text { Severe symptomatic } \\
\text { hypercalcemia }\end{array}$ \\
\hline present case & 44 & M & $\begin{array}{l}\text { W183C } \\
\text { exon } 3\end{array}$ & Gastrinoma & Moderate hypercalcemia \\
\hline
\end{tabular}

F: female; M: male.

*The mutation of the MEN1 gene was identified in a patient with carcinoma who presented hyperplasia in the rest of the parathyroid glands without showing other tumors related to MEN1. The mutation was not identified in examinations of four family members (three sisters and one daughter). 
can lead to suspicion of this possibility. Nevertheless, the diagnosis of parathyroid carcinoma is usually made when the patient undergoes surgery for HPT.

Our patient underwent surgery for the treatment for HPT associated with MEN1. There was no suspicion prior to surgery that a parathyroid carcinoma was present as, contrary to expectations the hypercalcemia was moderate and there was nothing in the imaging tests that suggested this possibility. During the surgery, a parathyroid with characteristics associated with malignancy was noted and the histology confirmed that it was a carcinoma, the definitive criteria being the infiltration of surrounding fatty tissue. Although parathyroid carcinoma is generally associated with severe hypercalcemias, sometimes, as in our case, hypercalcemia is moderate. Parathyroid carcinoma may also exist without hypercalcemia. In such cases it is associated with a major malignancy and a poor prognosis. $^{20,21}$

Of the five cases of parathyroid carcinoma associated with MEN1 in the literature, four presented with severe symptomatic hypercalcemia (Table 1). As for the concurrence of other tumors associated with MEN1, in the case herein presented the primary diagnosis was of gastrinoma, although the HPT appears to have existed previously but was not recognised as was shown based on the hypercalcemia present 5 years before the diagnosis of gastrinoma. In addition, two non-functional adrenal adenomas were detected, tumors that may also be associated with MEN1. In one of the reviewed cases of parathyroid carcinoma in patients with MEN1, although the presence of a mutation of the MEN1 gene was detected, the syndrome actually was not present, since neither he nor his family members had other associated tumors. ${ }^{18}$ The other cases presented pancreatic tumors, of which all except one were gastrinomas (Table 1).

As for the treatment of the parathyroid carcinoma, it is based on the complete surgical removal of the lesion and the surrounding infiltrated tissues as well as a homolateral hemithyroidectomy. The best demonstration of the success of the surgery is the normalization of the calcemia and PTH levels. The follow-up requires frequent periodic determinations of the calcium concentration in addition to imaging studies. When there is any suspicion of recurrence, a second surgery is indicated.
Parathyroid carcinoma associated with MEN1 can present the added difficulty that the reappearance of hypercalcemia might not be due to a recurrence of the parathyroid carcinoma but rather be secondary to adenomatous hyperplasia of other parathyroids or of remaining parathyroid tissue, depending on the extent of removal in the first operation. In either case, a new surgery is indicated.

Other treatments are more controversial, such as radiotherapy to prevent or control the local recurrence of parathyroid carcinoma. Although parathyroid carcinoma has traditionally been considered to be resistant to radiotherapy, some studies have shown it to be beneficial and some authors recommend its adjuvant use in a systematic fashion. ${ }^{22,23}$ When a surgical resection is not possible or there has been metastatic dissemination, the use of biphosphonates or calcimimetics is effective in the majority of cases in controlling the hypercalcemia. ${ }^{24}$

Even when a normalization of calcemia after surgery is achieved, patients frequently experience recurrences, which makes long-term follow-up mandatory. ${ }^{9}$ Our patient, 6 years after pancreatic surgery and 3 years after parathyroid surgery, has not shown any evidence of recurrence but nevertheless continues with a periodic follow-up.

In conclusion, germline mutations of the MEN1 gene do not appear to confer a greater risk of presentation of parathyroid carcinoma according to the few cases referring to this syndrome in the literature and the same holds true for the cases of parathyroid carcinoma occurring in sporadic fashion.

\section{REFERENCES}

1. Carling T, 2005 Multiple endocrine neoplasia syndrome: genetic basis for clinical management. Curr Opin Oncology 17: 7-12.

2. Marx S, Spiegel AM, Skarulis MC, Doppman JL, Collins FS, Liotta LA, 1998 Multiple endocrine neoplasia type 1: clinical and genetics topics. Ann Intern Med 129: 484-494.

3. Wynne AG, van Heerden J, Carney JA, Fitzpatrick LA, 1992 Parathyroid carcinoma: clinical and pathologic features in 43 patients. Medicine (Baltimore) 71: 197205.

4. Troilo VL, D’Eredità G, Fischetti F, Berardi T, 2009 Parathyroid cancer as rare cause of primary hyperparathyroidism. Case report and review of the literature. G 
Chir 30: 432-436.

5. Schantz A, Castleman B, 1973 Parathyroid carcinoma: a study of 70 cases. Cancer 31: 600-605.

6. Bondeson L, Sandelin K, Grimelius L, 1993 Histopathological variables and DNA cytometry in parathyroid carcinoma. Am J Surg Pathol 17: 820-829.

7. Erikson LA, Jin L, Papotti M, Lloyd RV, 2002 Oxyphil parathyroid carcinomas: a clinicopathologic and immunohistochemical study of 10 cases. Am J Surg Pathol 26: 344-349.

8. Tan MH, Morrison C, Wang P, et al, 2004 Loss of parafibromin immunoreactivity is a distinguishing feature of parathyroid carcinoma. Clin Cancer Res 10: 6629-6637.

9. Gill AJ, Clarkson A, Gimm O, et al 2006 Loss of nuclear expression of parafibromin distinguishes parathyroid carcinomas and hyperparathyroidism-jaw tumor (HPTJT) syndrome-related adenomas from sporadic parathyroid adenomas and hyperplasias. Am J Surg Pathol 30: 1140-1149.

10. Shane E, 2001 Clinical review 122: Parathyroid carcinoma. J Clin Endocrinol Metab 86: 485-493.

11. Mizusawa N, Uchino S, Iwata T, et al, 2006 Genetic analyses in patients with familial isolated hyperparathyroidism-jaw tumor syndrome. Clin Endocrinol 65: 9-16.

12. Shattuck TM, Välimäki S, Obara T, et al, 2003 Somatic and germ-line mutations of the HRPT2 gene in sporadic parathyroid carcinoma. N Engl J Med 349: 1722-1729.

13. Haven CJ, van Puijenbroek M, Tan MH, et al 2007 Identification of MEN1 and HRPT2 somatic mutations in paraffin-embedded (sporadic) parathyroid carcinomas. Clin Endocrinol 67: 370-376.

14. Hannan FM, Nesbit MA, Christie PT, Fratter C, Dudley NE, Thakker RV, 2008 Familial isolated primary hyperparathyroidism caused by mutations of the MEN1 gene. Nat Clin Endocrinology Metab 4: 53-58.

15. Kelly TG, Shattuck TM, Reyes-Múgica M, et al 2006
Surveillance for early detection of aggressive parathyroid disease: carcinoma and atypical adenoma in familial isolated hyperparathyroidism associated with a germline HRPT2 mutation. J Bone Miner Res 21: 1666-1671.

16. Agha A, Carpenter R, Bhattacharya S, Edmonson SJ, Carlsen E, Monson JP, 2007 Parathyroid carcinoma in multiple endocrine neoplasia type 1 (MEN1) syndrome: two case reports of an unrecognised entity. J Endocrinol Invest 30: 145-149.

17. Shih RY, Fackler S, Maturo S, True MW, Brennan J, Wells D, 2009 Parathyroid carcinoma in multiple endocrine neoplasia type 1 with a classic germline mutation. Endocr Pract 15: 567-572.

18. Sato M, Miyauchi A, Namihira H, et al, 2000 A newly recognized germline mutation of MEN1 gene identified in a patient with parathyroid adenoma and carcinoma. Endocrine 12: 223-226.

19. Dionisi S, Minisola S, Pepe J, et al, 2002 Concurrent parathyroid adenomas and carcinoma in the setting of multiple endocrine neoplasia type 1: presentation as hypercalcemic crisis. Mayo Clin Proc 77: 866-869.

20. Wilkins BJ, Lewis JS, 2009 Non-Functional Parathyroid Carcinoma: A Review of the Literature and Report of a Case Requiring Extensive Surgery. Head Neck Pathol 3: 140-149.

21. Fernandez-Ranvier GG, Jensen K, Khanafshar E, et al, 2007 Nonfunctioning parathyroid carcinoma: case report and review of literature. Endoc Pract 13: 750-757.

22. Munson ND, Foote RL, Northcutt RC, et al, 2003 Parathyroid carcinoma: is there a role for adjuvant radiation therapy?. Cancer 98: 2378-2384.

23. Busaidy NL, Jimenez C, Habra MA, et al, 2004 Parathyroid carcinoma: a 22-year experience. Head Neck 26: 716-726.

24. Silverberg SJ, Rubin MR, Faiman C, et al, 2007 Cinacalcet hydrochloride reduces the serum calcium concentration in inoperable parathyroid carcinoma. J Clin Endocrinol Metabol 92: 3803-3808. 